Cite this: RSC Advances, 2013, 3 9005

Received 20th February 2013,

Accepted 1st April 2013

DOI: $10.1039 / \mathrm{c} 3 \mathrm{ra} 40847 \mathrm{~g}$

www.rsc.org/advances

\title{
An insight into the effect of nitrogen doping on the performance of a reduced graphene oxide counter electrode for dye-sensitized solar cells $†$
}

\author{
Xiaoying Zhang, ${ }^{\text {ab }}$ Shuping Pang, ${ }^{a}$ Xiao Chen, ${ }^{a}$ Kejun Zhang, ${ }^{\text {ab }}$ Zhihong Liu, ${ }^{a}$ \\ Xinhong Zhou' and Guanglei Cui ${ }^{* a}$
}

\begin{abstract}
$\mathrm{N}$ doped reduced graphene oxide nanosheets (N-GNSs) with controllable N-doping and integrated with stainless steel are explored as an efficient metal-free catalyst for the $\mathrm{I}_{3}{ }^{-}$reduction reaction, revealing evident correlations between the electrocatalytic activity and the $\mathrm{N}$-doping content of graphene. In addition, it is found that $V_{\mathrm{OC}}$ is enhanced by about $60 \mathrm{mV}$ for the cells constructed with N-GNSs and the increment of $V_{O C}$ increases with a decreasing amount of $\mathrm{N}$-doping, as expected from the trend in the flatband potential $\left(E_{\mathrm{fb}}\right)$.
\end{abstract}

\section{Introduction}

Dye-sensitized solar cells (DSCs) introduced by Grätzel and O'Regan two decades ago have aroused an intense interest owing to their low production cost and relatively high light-toelectricity conversion efficiency $(\eta) .{ }^{1}$ In a typical DSC, the photon-induced oxidation of a sensitizer occurs at the $\mathrm{TiO}_{2}$ photoanode, while the reduction of the standard redox species, iodide/triiodide $\left(\mathrm{I}^{-} / \mathrm{I}_{3}{ }^{-}\right)$, used as a mediator in regenerating the sensitizer after electron injection, occurs at the counter electrode (CE). ${ }^{2-4}$ However, the reduction of $\mathrm{I}_{3}{ }^{-}$is sluggish in nature and traditionally requires the exclusive use of Pt-based catalysts. ${ }^{5}$ Because of the high cost and rare source of Pt, substantial efforts have been dedicated to developing DSC CEs using non-noble metal catalysts, including carbonaceous materials $^{6,7}$, conductive polymer ${ }^{8,9}$ and inorganic materials. $^{10-12}$

Graphene nanosheets (GNSs), a monolayer of carbon atoms covalently bonded into a hexagonal lattice, have received a great deal of attention among various options, because of their exceptional surface area, high optical transparency, as well as excellent thermal/chemical stability. ${ }^{13-15}$ Perfect graphene does not seem to be the right candidate for a DSC CE on account of the limited number of active sites for the $\mathrm{I}_{3}{ }^{-} / \mathrm{I}^{-}$ electro-catalysis, although it possesses an extremely high conductivity. ${ }^{16,17}$ There seems to be a general consensus that

\footnotetext{
${ }^{a}$ Qingdao Institute of Bioenergy and Bioprocess Technology, Chinese Academy of Sciences, Qingdao 266101, P. R. China. E-mail: cuigl@qibebt.ac.cn

${ }^{b}$ University of Chinese Academy of Sciences, Beijing, 100080, P. R. China ${ }^{c}$ Qingdao University of Science and Technology, Qingdao, 266101, P. R. China $\dagger$ Electronic supplementary information (ESI) available: High-resolution C1s and N1s XPS spectra for N-GNSs and the simulation data for EIS. See DOI: 10.1039/ c3ra40847g
}

the performance of DSCs employing a GNSs CE is mainly contingent upon the electronic structure and surface chemistry of graphene. Kavan et al., for example, have suggested that the electrocatalytic activity for the $\mathrm{I}_{3}{ }^{-}$reduction might be bound up with the oxygen-containing functional groups and the lattice surface defects of graphene nanosheets. ${ }^{18}$ Furthermore, Roy-Mayhew et al. presented graphene CEs with controlled $\mathrm{C}$ : O ratios and they found that the electrochemical properties are proportional to the concentration of oxygencontaining functional groups in a graphene sheet. ${ }^{19}$ However, DSCs utilizing partially reduced graphene oxide as the CE exhibited a low conversion efficiency equal to $40 \%$ of that of a Pt-based cell, because such rich oxygen-containing groups decrease the electrical conductivity of graphene. Therefore, it is suggested that the electrical conductivity of GNSs significantly affects their electro-catalytical behavior and their photoelectric performance.

Chemical doping with nitrogen $(\mathrm{N})$ atoms is proved to be an effective strategy to regulate the electronic structure of graphene and thus produce systematic changes in the

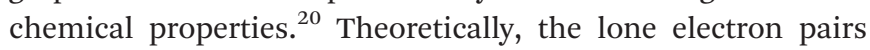
of $\mathrm{N}$ atoms can form a delocalized conjugated system with the $\mathrm{sp}^{2}$-hybridized carbon frameworks and can be allocated in the conduction band of the pristine graphene, resulting in a consequent shift of the Fermi energy. ${ }^{21}$ More importantly, when the $\mathrm{N}$ atom is bonded with a carbon framework, it introduces a defect in the nearby sites due to difference in bond length and atomic size, and induces a higher positive charge distribution on the adjacent carbon atoms because of the electron-withdrawing ability of $\mathrm{N}$, and thereby strongly enhance the reactivity and electrocatalytic performance of graphene. ${ }^{22}$ Recent reports have demonstrated that N-doped graphene nanosheets (N-GNS) show excellent electrocatalytic 
activity toward the $\mathrm{I}_{3}{ }^{-}$reduction, ${ }^{23,24}$ which reveals the possibility of replacing expensive Pt-based catalysts in a DSC system. However, the impact of the degree of N-doping functionalization on the apparent electrocatalytic performance has not been studied in detail.

Herein, we provide a thorough analysis of DSCs based on N-GNSs, synthesized by the heat-treatment of graphite oxide (GO) under an ammonia atmosphere at a temperature range of $600-900{ }^{\circ} \mathrm{C}$. The degree of $\mathrm{N}$-doping functionalization can be tuned by the elevated temperatures. Nevertheless, the change in electronic conductivity of N-GNSs is inevitably concomitant with the N-doping on the carbon material and its impact on the apparent electrocatalytic performance could not be ignored as mentioned above. In order to directly exploit the effect of the $\mathrm{N}$-doping functionalization on the electrocatalytic activity of graphene nanosheets, a stainless steel mesh was chosen as the current collector instead of fluorine doped tin oxide (FTO), since its excellent electrical conductivity and intimate contact with N-GNSs is desired to compensate the variable conductivity from $\mathrm{N}$-doping at different temperatures. We investigate the $\mathrm{N}$-doping influence by X-ray photoelectron spectroscopy (XPS) characterization, cyclic voltammetry (CV), electrochemical impedance spectroscopy (EIS) and MottSchottky analysis. These results lead to insights into the degree of doping at various temperatures, the role played by the N-doping content in the reaction activity and the flat-band potential shift of the resultant graphene sheets.

\section{Preparation and characterization of N-GNSs}

N-GNSs were synthesized from graphite powder according to our previous study. ${ }^{25}$ Graphite oxide (GO) was prepared as previously reported by Hummers and Offeman using commercial graphite powder (Aldrich, powder, 20 micron, synthetic). The GO obtained was then dried at $60{ }^{\circ} \mathrm{C}$ for $4 \mathrm{~h}$ in a vacuum oven, and followed by heat treatment at $600-900{ }^{\circ} \mathrm{C}$ for $2 \mathrm{~h}$ under an ammonia atmosphere to obtain N-GNSs.

The CE was prepared by dispersing N-GNSs and polytetrafluoroethylene (PTFE) in distilled water, with a weight ratio of $90: 10$, respectively. The resultant slurry was pasted on a 0.5 $\mathrm{cm} \times 0.5 \mathrm{~cm}$ square stainless steel current-collector pressured at $15 \mathrm{MPa}$. The DSC with an active area of $0.16 \mathrm{~cm}^{2}$ was constructed as described previously in the literature. ${ }^{5}$ The liquid electrolyte was composed of $0.06 \mathrm{M} \mathrm{LiI}, 0.6 \mathrm{M} \mathrm{1,2-}$ dimethyl-3-propylimidazolium iodide (DMPII), $0.03 \mathrm{M} \mathrm{I}_{2}, 0.5$ $\mathrm{M}$ 4-tert-butylpyridine (TBP), and $0.1 \mathrm{M}$ guanidinium thiocyanate with acetonitrile as the solvent.

The current-voltage $(I-V)$ characteristics of the DSCs were recorded using a computer-programmed Keithley 2420 source/ meter. A 300W Xe arc lamp (Oriel) with an AM 1.5 solar simulating filter for spectral correction served as the light source, and its light intensity was adjusted to $100 \mathrm{~mW} \mathrm{~cm}^{-2}$ by using a standard Si solar cell.

The cyclic voltammetry (CV) of samples was measured in a three-electrode one-compartment cell with the gained N-GNSs
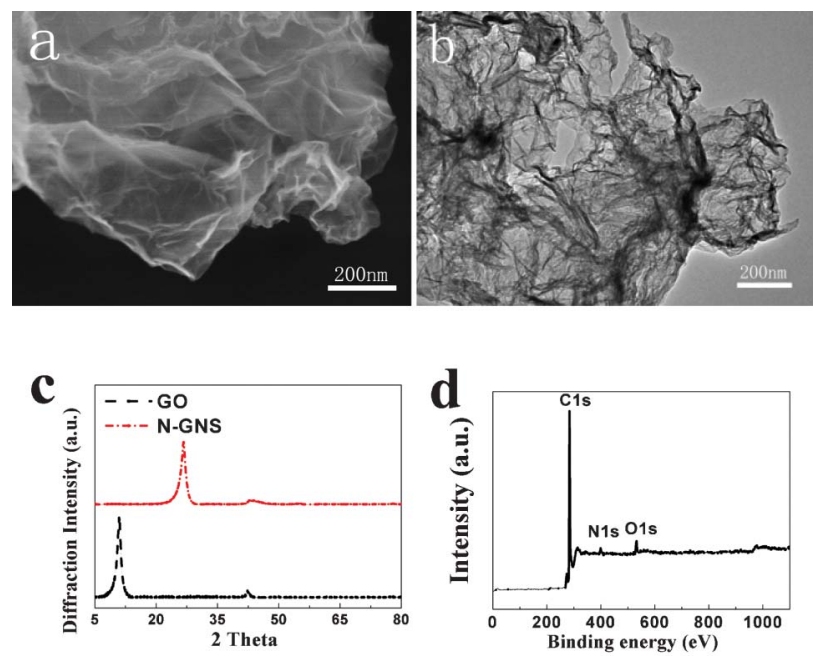

Fig. 1 Representative SEM (a) and TEM (b) images of the N-GNSs, (c) XRD patterns of GO and the as-prepared N-GNS, (d) XPS spectra of the N-GNS.

as the work electrode, a Pt foil as the counter electrode and a $\mathrm{Ag} / \mathrm{Ag}^{+}$as the reference electrode dipped in an acetonitrile solution of $10 \mathrm{mM} \mathrm{LiI}, 1 \mathrm{mM} \mathrm{I}_{2}$, and $0.1 \mathrm{M} \mathrm{LiClO}_{4}$ at a scan rate of $20 \mathrm{mV} \mathrm{s}^{-1}$. Mott-Schottky analysis was performed in a three-electrode cell at $1000 \mathrm{~Hz}$. The electrochemical impedance spectroscopy (EIS) experiments were conducted from $100 \mathrm{kHz}$ to $100 \mathrm{mHz}$ with an AC modulation signal of $10 \mathrm{mV}$. The EIS results were analyzed using the Zsimpwin software.

Morphological information was attained from field emission scanning electron microscopy (FESEM, HITACHI S-4800). X-ray diffraction (XRD) patterns were recorded with a BrukerAXS Micro-diffractometer (D8 ADVANCE).

\section{Results and discussion}

From the scanning electron microscopy (SEM) image (Fig. 1a) of the product, we can clearly observe the curled and overlapped nanosheets. Furthermore, the transmission electron microscopy (TEM) image (Fig. 1b) reveals that the N-GNS exhibits a typical wrinkled structure with corrugation and scrolling, resulting from thermodynamically stable bending. ${ }^{26}$ Both the SEM and TEM images indicate that the twodimensional structure of the graphene nanosheets is well maintained after doping with $\mathrm{N}$. The XRD patterns of the GO and N-GNS are presented in Fig. 1c. Compared to the GO pattern, the peak centered at a $2 \theta$ angle of about $11^{\circ}$ has disappeared in the N-GNS pattern, whilst the peak at about $26.5^{\circ}$ has emerged, which is due to the loss of oxygen containing groups and the formation of graphene. ${ }^{27}$ Additionally, an obvious $\mathrm{N}$ peak is clearly detected from the XPS spectra of N-GNS (Fig. 1d), revealing the presence of $\mathrm{N}$ in the graphene nanosheets. The 01s peak mainly arises from thermally stable groups in GO, such as quinine, besides some oxygen or water absorbed on to the surface of the N-GNSs. ${ }^{28}$ 

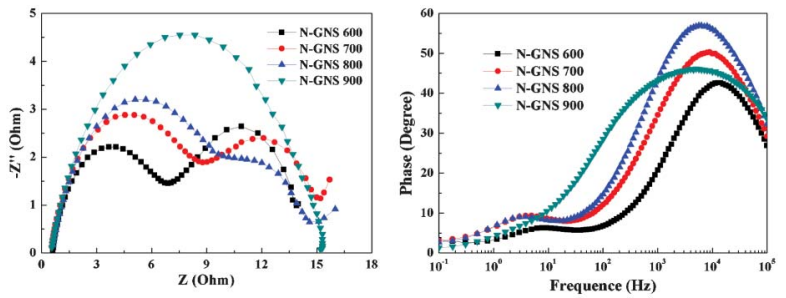

Fig. 2 Impedance spectra of the symmetric cells with two identical CEs of $\mathrm{N}$-GNSs in the measured frequency range from $100 \mathrm{kHz}$ to $100 \mathrm{mHz}$, (a) Nyquist plots and (b) Bode phase plots.

In order to elucidate the relation between the electrochemical property and the N-doping content of the as-prepared N-GNSs samples, the electrochemical impedance spectra (EIS) was measured in a symmetric sandwich cell configuration consisting of two identical CEs. ${ }^{29}$ The Nyquist plot and the Bode phase plot are illustrated in Fig. 2. For this system, a typical EIS spectrum for a DSC exhibits two semicircles in the Nyquist plot or two characteristic frequency peaks in a Bode phase plot. $^{30}$ According to previous studies, the highfrequency (around $100 \mathrm{KHz}$ ) intercept on the real axis represents the series resistance $\left(R_{\mathrm{s}}\right) .{ }^{31}$ The characteristic in frequency regions between $1 \mathrm{kHz}$ and $100 \mathrm{kHz}$ is assigned to the charge-transfer process on the $\mathrm{CE}$ while the ones in the low-frequency is attributed to the Nernst diffusion impedance of the $\mathrm{I}^{-} / \mathrm{I}_{3}{ }^{-}$redox species in the electrolyte. It is worth noting that the N-GNSs samples are close to each other in $R_{\mathrm{s}}$, as we expected, confirming that the difference of conductivity among various N-GNSs CEs can be neglected by using a stainless steel mesh as the current collector. $R_{\mathrm{ct}}$ is an effective and widely used parameter for investigating the charge transfer process and thereby for evaluating the catalytic activity of a catalyst. A large $R_{\mathrm{ct}}$, presented by the semicircle in the high-frequency regime, indicates a sluggish electron transfer, whereas a small $R_{\mathrm{ct}}$ implies a facile electron transfer and thus ensures a higher $J_{\mathrm{SC}}$ for the pertinent DSC. ${ }^{32}$ As shown in Table S1 $\dagger$, the simulated $R_{\mathrm{ct}}$ values are in the order of N-GNS $600\left(5.76 \Omega \mathrm{cm}^{-2}\right)<\mathrm{N}-$ GNS $700\left(7.93 \Omega \mathrm{cm}^{-2}\right)<\mathrm{N}-$ GNS $800\left(9.07 \Omega \mathrm{cm}^{-2}\right)<\mathrm{N}-\mathrm{GNS} 900\left(12.97 \Omega \mathrm{cm}^{-2}\right)$. Correspondingly, the characteristic frequency shown in the Bode phase plots is in the decreasing order of N-GNS $600>$ N-GNS $700>\mathrm{N}$-GNS $800>\mathrm{N}$-GNS 900, which is positively correlated with the catalytic activity. ${ }^{33}$ These results illustrate that the activity of the N-GNSs is in the following order: N-GNS $600>\mathrm{N}-\mathrm{GNS} 700>\mathrm{N}-\mathrm{GNS} 800>\mathrm{N}-\mathrm{GNS} 900$.

To gain further insight into the catalytic properties of the as-prepared N-GNS CE, cyclic voltammetry (CV) was conducted in a three-electrode one-compartment cell with the gained $\mathrm{N}$-GNS as the work electrode, Pt foil as the counter electrode and an $\mathrm{Ag} / \mathrm{Ag}^{+}$as the reference. As shown in Fig. 3, the Pt electrodes display two typical pairs of peaks, where the relatively negative pair is assigned to the redox reaction (1) and the positive one is ascribed to redox reaction (2). ${ }^{34}$

$$
\mathrm{I}_{3}^{-}+2 \mathrm{e}^{-}=3 \mathrm{I}^{-}
$$

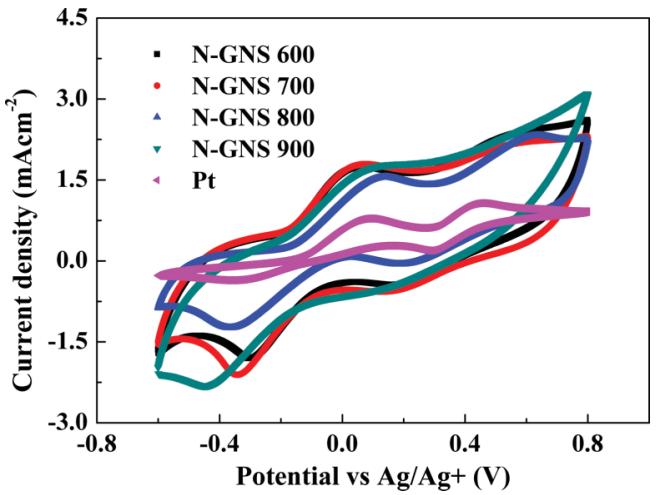

Fig. 3 Cyclic voltammograms of N-GNS and Pt electrodes at a scan rate of 20 $\mathrm{mV} \mathrm{s}^{-1}$ in a $10 \mathrm{mM}$ Lil and $1 \mathrm{mM} \mathrm{I}_{2}$ acetontrile solution containing $0.1 \mathrm{M} \mathrm{LiClO}_{4}$ as the supporting electrolyte.

$$
3 \mathrm{I}_{2}+2 \mathrm{e}^{-}=2 \mathrm{I}_{3}^{-}
$$

All the N-GNS samples present two pairs of well-defined peaks and a similar peak potential to $\mathrm{Pt}$, which indicate an excellent electrocatalytic characteristic like Pt. The value of peak separation $\left(\Delta E_{\mathrm{p}}\right)$ for $\mathrm{I}_{3}{ }^{-} / \mathrm{I}^{-}$is N-GNS $600(0.369 \mathrm{~V})<$ N-GNS $700(0.416 \mathrm{~V})<\mathrm{N}$-GNS $800(0.506 \mathrm{~V})<\mathrm{N}$-GNS 900 $(0.604 \mathrm{~V})$. It is deduced that the electron transfer rate of the N-GNSs presents the following order: N-GNS $600>$ N-GNS 700 $>\mathrm{N}$-GNS $800>\mathrm{N}$-GNS 900, according to the previous literature ${ }^{35}$ which is in accordance with the EIS results.

XPS was used to investigate the structural differences of these N-GNS films at different temperatures, shown in Fig. 4 and Fig. S1.† The atomic content of $\mathrm{C}, \mathrm{N}$ and $\mathrm{O}$ elements in these samples calculated from the XPS spectra is quantitatively depicted in Table 1.

XPS of C1s ranging from 282 to $292 \mathrm{eV}$ is shown in Fig. $4 \mathrm{~b}$. Generally, there are several different $\mathrm{C}$ groups in chemically synthesized graphene nanosheets, which are characterized by the appearance of several spectral peaks. The main peak of C1s at $284.8 \mathrm{eV}$ is related to the graphite-like $\mathrm{sp}^{2} \mathrm{C}(\mathrm{C} 1)$, indicating $\mathbf{a}$

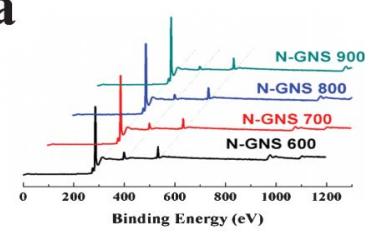

C

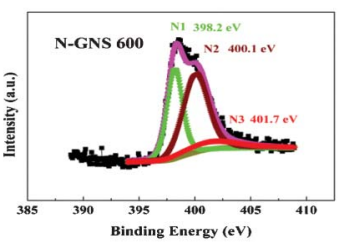

b

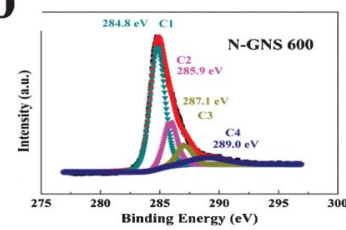

d

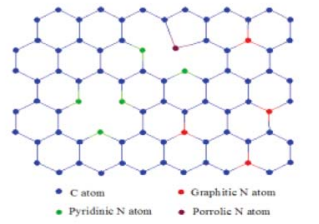

Fig. 4 (a) A full range of XPS spectra of N-GNSs samples at different temperatures, (b) the C1s XPS spectrum and (c) N1s XPS spectrum of the N-GNS 600 , (d) schematic structure of a N-GNS. 
Table 1 Distribution of the element species obtained from the de-convolution of the C1s, N1s and O1s peaks by XPS

\begin{tabular}{|c|c|c|c|c|}
\hline Entry & $\begin{array}{l}\text { at.\% } \\
\text { N-GNS } 600\end{array}$ & $\begin{array}{l}\text { at.\% } \\
\text { N-GNS } 700\end{array}$ & $\begin{array}{l}\text { at.\% } \\
\text { N-GNS } 800\end{array}$ & $\begin{array}{l}\text { at.\% } \\
\text { N-GNS } 900\end{array}$ \\
\hline Total carbon $(\mathrm{C})$ & 85.06 & 85.39 & 86.75 & 88.38 \\
\hline Total nitrogen $(\mathrm{N})$ & 7.31 & 7.09 & 5.99 & 3.91 \\
\hline Total oxygen $(\mathrm{O})$ & 7.63 & 7.52 & 7.26 & 7.71 \\
\hline Pyridinic nitrogen (N1) & 2.72 & 2.05 & 1.99 & 1.62 \\
\hline Pyrrolic nitrogen (N2) & 3.83 & 3.17 & 2.69 & 1.51 \\
\hline Graphitic nitrogen (N3) & 0.75 & 1.87 & 1.31 & 0.78 \\
\hline
\end{tabular}

that most of the $\mathrm{C}$ atoms in the N-GNS are arranged in a conjugated honeycomb lattice. While another two weak peaks at 285.7 and $287.5 \mathrm{eV}$ suggest the formation of the different bonding structures of the $\mathrm{C}-\mathrm{N}$ bonds, corresponding to the $\mathrm{N}-\mathrm{sp}^{2} \mathrm{C}(\mathrm{C} 2)$ and $\mathrm{N}-\mathrm{sp}^{3} \mathrm{C}$ bonds (C3), respectively, and it would originate from the substitution of the $\mathrm{N}$ atoms, defects or the edge of the graphene sheets. ${ }^{28}$ As is well-known, it is difficult to clearly discern the peak of $\mathrm{C}=\mathrm{O}$, since it is overlaid with $\mathrm{C}-\mathrm{N}$ around the binding energy of $287.5 \pm 0.5 \mathrm{eV}$. The small peaks at $289 \mathrm{eV}$ correspond to $\mathrm{C}-\mathrm{C}=\mathrm{O}(\mathrm{C} 4)$.

The N1s peaks of the N-GNSs samples can be fitted into three peaks centered at 398.2, 400.1 and $401.7 \mathrm{eV}$, indicating that the $\mathrm{N}$ atoms are in the three different bonding characters inserted into the graphene network (Fig. 4c). The peaks at 398.2 and $400.1 \mathrm{eV}$ correspond to "pyridinic" (N1) and "pyrrolic" $\mathrm{N}$ (N2), respectively. They refer to the $\mathrm{N}$ atoms which are located in a $\pi$ conjugated system and contribute to the $\pi$ system with one or two p-electrons, respectively. The peak at $401.7 \mathrm{eV}$ corresponds to "graphitic" N (N3), which refers to the $\mathrm{N}$ atoms replacing the $\mathrm{C}$ atoms inside the graphene layers. These results demonstrated the successful doping of $\mathrm{N}$ into the graphitic layer of graphene. Their molecular bonding structures are depicted clearly in Fig. 4 d.

It can be seen from Table 1 that the $\mathrm{N}$ atomic content decreases monotonically from $4.16 \%$ to $1.71 \%$ with an increase of the annealing temperature from $600{ }^{\circ} \mathrm{C}$ to 900 ${ }^{\circ} \mathrm{C}$, and that the pyridinic and pyrrolic $\mathrm{N}$ species (N1 + N2) are predominant in these N-GNS samples. Although the mechanism of $\mathrm{N}$ doping and the formation process of three types of $\mathrm{N}$ species remain unclear, it is unambiguous that the incorporation of $\mathrm{N}$ atoms into the flat lattice of graphene and the bonding reconstruction can be controlled by the annealing temperature. In association with our XPS analysis of the $\mathrm{N}$-GNSs, that is, with the increase of the annealing temperature from 600 to $900{ }^{\circ} \mathrm{C}$, the content of $\mathrm{O}$ is kept constant while that of $\mathrm{N}$ is significantly alleviated. Therefore, it is reasonable to believe that an enhancement of the $\mathrm{N}$-doping content is crucial for the promotion of the electrocatalytic reaction in the triiodide reduction.

Subsequently, the photovoltaic performances of DSCs dependent on the N-GNSs CEs were evaluated as shown in Fig. 5 and the detailed parameters are summarized in Table 2. As a reference, the DSC with typical Pt has an open-circuit voltage $\left(V_{\mathrm{OC}}\right)$ of $0.796 \mathrm{~V}$, a short-circuit current density $\left(J_{\mathrm{SC}}\right)$ of
$13.26 \mathrm{~mA} \mathrm{~cm}{ }^{-2}$ and a fill factor $(F F)$ of $69.39 \%$, leading to a conversion efficiency $(\eta)$ of $7.33 \%$. In contrast to earlier reports, the $F F$ values of these N-GNSs have been highly enhanced and exceeded $71 \% .^{24}$ This could be attributed to the robust electronic bonding between the N-GNSs and the stainless steel substrate, proved by a previous report. ${ }^{36}$ Consequently, the energy conversion efficiencies of the cells with N-GNSs yield $8.03 \%$ for N-GNS 600, 7.85\% for N-GNS 700, $7.69 \%$ for N-GNS 800 and $7.65 \%$ for N-GNS 900, respectively. They are superior to that of cells with Pt CEs under the same testing conditions.

Notably, the $V_{\text {OC }}$ values of the as-prepared N-GNSs-stainless steel cell are all larger by about $60 \mathrm{mV}$ than that of the Pt CE cell and GNS (Fig. S2, ESI $\dagger$ ), indicating that the N-doping may be responsible for the observed advantages in $V_{\text {OC. After }}$ $\mathrm{N}$-doping, the surface electronic structure and energy level of the host metal are drastically changed, which results in the shift of the flat-band potential $\left(E_{\mathrm{fb}}\right)$ level and thereby strongly enhances the reactivity and electrocatalytic performance of graphene. ${ }^{37}$ That means that the charge transport resistance in the cells using N-GNSs is much smaller, producing a high electron density on the conduction band of $\mathrm{TiO}_{2}$, thereby causing the increase in $V_{\mathrm{OC}} \cdot{ }^{36,38}$

Mott-Schottky (MS) analysis is a common tool used to investigate the semiconductor-electrolyte interface. The inverse square of the capacitance $\left(C_{\mathrm{SC}}\right)$ of N-GNSs are plotted against applied potential bias in Fig. 6 (MS plots), along with the linear fits in the depletion regions. N-GNS is always reported as an n-type semiconductor. However, the presence of the physisorbed molecular oxygen may lead to the transformation of an n-type semiconductor to a p-type semiconductor. ${ }^{39,40}$ Herein, the obtained N-GNS CEs manifest the typical behavior

Table 2 Photovoltaic parameters ${ }^{a}$ of the DSCs using different kinds of CEs

\begin{tabular}{lllll}
\hline Samples & $V_{\text {OC }}(\mathrm{V})$ & $J_{\text {SC }}\left(\mathrm{mA} \mathrm{cm}^{-2}\right)$ & $F F(\%)$ & $\eta(\%)$ \\
\hline Pt & 0.796 & 13.26 & 69.39 & 7.33 \\
N-GNS 600 & 0.858 & 13.00 & 71.99 & 8.03 \\
N-GNS 700 & 0.862 & 12.59 & 71.91 & 7.85 \\
N-GNS 800 & 0.864 & 12.42 & 71.89 & 7.69 \\
N-GNS 900 & 0.868 & 12.26 & 71.87 & 7.65
\end{tabular}

${ }^{a} V_{\mathrm{OC}}$ : open-circuit voltage, $J_{\mathrm{SC}}$ : short-circuit current density, $F F$ : fill factor, $\eta$ : energy conversion efficiency. 


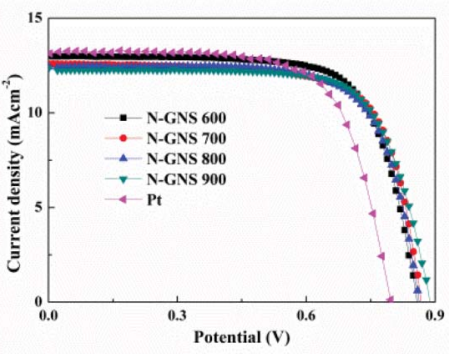

Fig. 5 Photocurrent-voltage (I-V) curves of the DSCs with different CEs of $\mathrm{N}-$ GNSs and Pt under 1 sun (AM 1.5) illumination.

for a "p" type semiconductor, confirmed by the negative slopes of the lines.

For a p-type semiconductor, the $E_{\mathrm{fb}}$ is calculated from the intercept on the abscissa, according to the following equation:

$$
\left(C_{\mathrm{SC}}\right)^{-2}=\frac{-2\left(E-E_{\mathrm{fb}}-k_{\mathrm{B}} T / e\right)}{e \kappa \varepsilon_{0} N A^{2}}
$$

where $\kappa, N$ and $A$ are the dielectric constant, density of acceptors within the space charge region and the effective surface area of the semiconductor.

As shown in Fig. 6, the positive shift of $E_{\mathrm{fb}}$ increases as the $\mathrm{N}$-doping content decreased, therefore, there are great possibility that the shift of $E_{\mathrm{fb}}$ may result in the systematic change of $V_{\mathrm{OC}}$ seen in Fig. 5.

\section{Conclusion}

In conclusion, N-GNSs with controllable N-doping were synthesized by the heat-treatment of GO under an ammonia atmosphere and then were pressed onto a stainless steel mesh to be scrutinized as low-cost CEs in DSCs. Profiting from the presence of stainless steel mesh, we evaluated the effect of the different content of N-doping groups on the catalytic activity of the materials. It is demonstrated that the performance of DSCs is dependent on $\mathrm{N}$-doping and that an increasing $\mathrm{N}$-doping results in an increase of the material's apparent catalytic activity. By incorporating the attractive features of abundant $\mathrm{N}$-doping and the excellent electronic conductivity together,

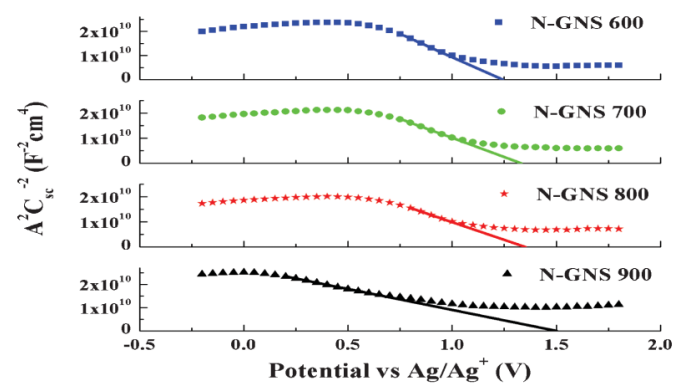

Fig. 6 Mott-Schottky plots of the N-GNS samples at different temperatures. the DSC using these CEs achieves a high energy conversion efficiency of $8.03 \%$ for N-GNS $600,7.85 \%$ for N-GNS 700 , $7.69 \%$ for N-GNS 800 and $7.65 \%$ for N-GNS 900, respectively, which is superior to that of cells with Pt (7.33\%) under the same testing conditions. Furthermore, we demonstrate that the different energy levels of the p-type semiconductors account for the different $V_{\mathrm{OC}}$ values of cells with N-GNS CEs.

\section{Acknowledgements}

We appreciate the support of the National Program on Key Basic Research Project of China (973 Program) (No. MOST2011CB935700), the "100 talents" program of the Chinese Academy of Sciences and the Natural Science Foundation of the Shandong Province (Grant No. ZR2011BQ024).

\section{Notes and references}

1 B. O'Regan and M. Gratzel, Nature, 1991, 353, 737-740.

2 G. Yu, J. Gao, J. C. Hummelen, F. Wudl and A. J. Heeger, Science, 1995, 270, 1789-1791.

3 Y. X. Gan, B. J. Gan, E. Clark, L. S. Su and L. H. Zhang, Mater. Res. Bull., 2012, 47, 2380-2388.

4 Y. X. Gan, B. J. Gan and L. Su, Mater. Sci. Eng., B, 2011, 176, 1197-1206.

5 A. Kay and M. Gratzel, Sol. Energy Mater. Sol. Cells, 1996, 44, 99-117.

6 K. Suzuki, M. Yamaguchi, M. Kumagai and S. Yanagida, Chem. Lett., 2003, 32, 28-29.

7 J. E. Trancik, S. C. Barton and J. Hone, Nano Lett., 2008, 8, 982-987.

8 Q. H. Li, J. H. Wu, Q. W. Tang, Z. Lan, P. J. Li, J. M. Lin and L. Q. Fan, Electrochem. Commun., 2008, 10, 1299-1302.

9 Y. Saito, T. Kitamura, Y. Wada and S. Yanagida, Chem. Lett., 2002, 1060-1061.

10 Q. W. Jiang, G. R. Li and X. P. Gao, Chem. Commun., 2009, 7603-7603.

11 M. Wu, X. Lin, A. Hagfeldt and T. Ma, Chem. Commun., 2011, 47, 4535-4537.

12 H. Sun, D. Qin, S. Huang, X. Guo, D. Li, Y. Luo and Q. Meng, Energy Environ. Sci., 2011, 4, 2630-2637.

13 A. K. Geim and K. S. Novoselov, Nat. Mater., 2007, 6, 183-191.

14 A. H. Castro Neto, F. Guinea, N. M. R. Peres, K. S. Novoselov and A. K. Geim, Rev. Mod. Phys., 2009, 81, 109-162.

15 R. R. Nair, P. Blake, A. N. Grigorenko, K. S. Novoselov, T. J. Booth, T. Stauber, N. M. R. Peres and A. K. Geim, Science, 2008, 320, 1308.

16 C. E. Banks, T. J. Davies, G. G. Wildgoose and R. G. Compton, Chem. Commun., 2005, 829-841.

17 T. N. Murakami and M. Gratzel, Inorg. Chim. Acta, 2008, 361, 572-580.

18 L. Kavan, J. H. Yum and M. Gratzel, ACS Nano, 2011, 5, 165-172.

19 J. D. Roy-Mayhew, D. J. Bozym, C. Punckt and I. A. Aksay, ACS Nano, 2010, 4, 6203-6211. 
20 T. O. Wehling, K. S. Novoselov, S. V. Morozov, E. E. Vdovin, M. I. Katsnelson, A. K. Geim and A. I. Lichtenstein, Nano Lett., 2008, 8, 173-177.

21 F. Cervantes-Sodi, G. Csanyi, S. Piscanec and A. C. Ferrari, Phys. Rev. B, 2008, 77.

22 K. Gong, F. Du, Z. Xia, M. Durstock and L. Dai, Science, 2009, 323, 760-764.

23 Y. Xue, J. Liu, H. Chen, R. Wang, D. Li, J. Qu and L. Dai, Angew. Chem., Int. Ed., 2012, 51, 12124-12127.

24 M.-Y. Yen, C.-K. Hsieh, C.-C. Teng, M.-C. Hsiao, P.-I. Liu, C.-C. M. Ma, M.-C. Tsai, C.-H. Tsai, Y.-R. Lin and T.Y. Chou, RSC Adv., 2012, 2, 2725-2728.

25 H. Wang, C. Zhang, Z. Liu, L. Wang, P. Han, H. Xu, K. Zhang, S. Dong, J. Yao and G. Cui, J. Mater. Chem., 2011, 21, 5430 .

26 J. C. Meyer, A. K. Geim, M. I. Katsnelson, K. S. Novoselov, T. J. Booth and S. Roth, Nature, 2007, 446, 60-63.

27 S. Dong, X. Chen, K. Zhang, L. Gu, L. Zhang, X. Zhou, L. Li, Z. Liu, P. Han, H. Xu, J. Yao, C. Zhang, X. Zhang, C. Shang, G. Cui and L. Chen, Chem. Commun., 2011, 47, 11291-11293.

28 D. Wei, Y. Liu, Y. Wang, H. Zhang, L. Huang and G. Yu, Nano Lett., 2009, 9, 1752-1758.

29 A. Hauch and A. Georg, Electrochim. Acta, 2001, 46, 3457-3466.
30 M. Adachi, M. Sakamoto, J. T. Jiu, Y. Ogata and S. Isoda, J. Phys. Chem. B, 2006, 110, 13872-13880.

31 Q. Wang, J. E. Moser and M. Gratzel, J. Phys. Chem. B, 2005, 109, 14945-14953.

32 C. Longo, A. F. Nogueira, M. A. De Paoli and H. Cachet, J. Phys. Chem. B, 2002, 106, 5925-5930.

33 L. Y. Han, N. Koide, Y. Chiba and T. Mitate, Appl. Phys. Lett., 2004, 84, 2433-2435.

34 A. I. Popov and D. H. Geske, J. Am. Chem. Soc., 1958, 80, 1340-1352.

35 M.-Y. Yen, C.-C. Teng, M.-C. Hsiao, P.-I. Liu, W.-P. Chuang, C.-C. M. Ma, C.-K. Hsieh, M.-C. Tsai and C.-H. Tsai, J. Mater. Chem., 2011, 21, 12880-12888.

36 M. Wu, Q. Zhang, J. Xiao, C. Ma, X. Lin, C. Miao, Y. He, Y. Gao, A. Hagfeldt and T. Ma, J. Mater. Chem., 2011, 21, 10761-10766.

37 Y. Hu, Z. Zheng, H. M. Jia, Y. W. Tang and L. Z. Zhang, J. Phys. Chem. C, 2008, 112, 13037-13042.

38 M. K. Wang, C. Gratzel, S. J. Moon, R. Humphry-Baker, N. Rossier-Iten, S. M. Zakeeruddin and M. Gratzel, Adv. Funct. Mater., 2009, 19, 2163-2172.

39 X. Li, H. Wang, J. T. Robinson, H. Sanchez, G. Diankov and H. Dai, J. Am. Chem. Soc., 2009, 131, 15939-15944.

40 C. Zhang, L. Fu, N. Liu, M. Liu, Y. Wang and Z. Liu, Adv. Mater., 2011, 23, 1020-1024. 